\title{
Uso do cetoprofeno sistêmico para a diminuição do estresse após mochação com ferro quente em bezerros Holandeses
}

Sylvia Marquart Fontes Novo, Camila Cecilia Martin, Bruno Toledo Silva, Camila Costa Baccili, Juliana França dos Reis Costa, Rejane dos Santos Sousa, Karina Medici Madureira, José Eugênio Guimarães, Bruna Stanigher Barbosa, Viviani Gomes

Faculdade de Medicina Veterinária e Zootecnia, Universidade de São Paulo (USP), São Paulo, SP, Brasil

*Autor correspondente

e-mail: medvetsylvia@gmail.com

\section{Resumo}

O objetivo desta pesquisa foi avaliar o efeito do cetoprofeno na resposta inflamatória e comportamental de bezerros submetidos à mochação com ferro quente. Foram utilizados 16 bezerros machos Holandeses, com idade entre 3 a 4 meses. Os bezerros foram distribuídos em grupos que não receberam (Grupo 1, G1, n = 7) ou receberam $3 \mathrm{mg} / \mathrm{Kg}$ de cetoprofeno a 10\%, uma vez ao dia, durante cinco dias (Grupo 2, G2, n = 9), sendo a primeira dose administrada imediatamente antes da mochação. Para a mochação, os animais foram sedados com xilazina $2 \%(0,05 \mathrm{mg} / \mathrm{Kg}$ - IV), além da infiltração local com lidocaína ( $15 \mathrm{~mL})$. 0 botão germinativo foi retirado com bisturi e cauterizado com ferro quente, com posterior aplicação de pasta cicatrizante e repelente. Os animais foram avaliados antes da mochação (D0) e nos dias D1, D2, D3, D4, D7 e D10 após o procedimento. Nestes momentos, realizou-se o exame físico, pesagem, hemograma (contagem automática) e haptoglobina (espectrofotometria). 0 cortisol (Cortisol Siemens ${ }^{\circledR}$ Ref: LKCO1, Lot: 0403) foi determinado apenas no D0, D1 e D2. 0 comportamento dos bezerros foi avaliado pelos movimentos da cabeça e orelhas, esfregar a cabeça, inquietação, vocalização e brincar com o alimento e água; estas avaliações foram feitas 2, 4, 6, 24, 48, 72 e 96 horas após a mochação. A comparação entre os grupos foi realizada pelo teste T, e a análise no tempo (D0 ao D10) foi avaliada por cálculos de ANOVA para medidas repetidas. As análises foram consideradas significativas quando $\mathrm{P} \leq 0,05$. Não houve diferenças para os parâmetros vitais em relação aos tratamentos e ao longo do tempo. Na análise do eritrograma não observamos diferenças em relação aos tempos e entre os grupos. Em relação ao leucograma foi possível observar diminuição nos neutrófilos entre o D0 (3,37 $\left.\pm 1,39 \times 10^{3} / \mu \mathrm{L}\right)$ e D1 $\left(1,81 \pm 1,15 \times 10^{3} / \mu \mathrm{L}\right)$ apenas no G2. Os valores de haptoglobina não apresentaram diferenças entre os grupos. 0 cortisol apresentou uma tendência ao aumento entre D0 (1 $\pm 0,0 \mu \mathrm{g} / \mathrm{dL}) \mathrm{e}$ $\mathrm{D} 1(1,37 \pm 0,53 \mu \mathrm{g} / \mathrm{dL})$ apenas no G1 $(\mathrm{P}=0,06)$. $0 \mathrm{G} 2$ não apresentou diferenças entre D0 $(1,16 \pm 0,23 \mu \mathrm{g} /$ $\mathrm{dL})$ e $\mathrm{D} 1(1,01 \pm 0,03 \mu \mathrm{g} / \mathrm{dL})(\mathrm{P}=0,234)$. Comparando os grupos observamos uma diferença nos valores de 


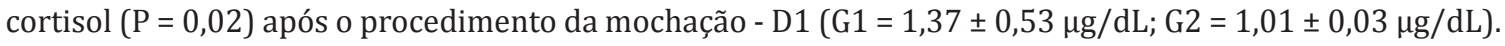
A avaliação comportamental mostrou inquietação, desconforto e aumento da frequência de movimentos da cabeça e orelhas em ambos os grupos, com aumento na intensidade após 4 horas. Essas alterações se mantiveram até 24 horas no G2 e 48 horas no G1. A mochação alterou o comportamento dos bezerros de ambos os grupos após o período de ação dos anestésicos. Os valores do cortisol demonstraram que o uso do cetoprofeno provavelmente diminui a dor e que culminou com o menor nível de estresse associado aos menores valores de cortisol observado no grupo tratado. 